\title{
Managing Partnership Uncertainty for Sustainable Services: A Conceptual Model
}

\author{
Christopher Durugbo \\ Department of Management, University of Bristol, Bristol, BS8 1TN, United Kingdom \\ Christopher.Durugbo@Bristol.ac.uk
}

\begin{abstract}
The paper presents the findings of a qualitative analysis that makes use of literature to determine the nature of uncertainties that characterises industrial collaborations for providing sustainable services. It aims to propose a conceptual model of partnership uncertainty management for sustainable services. The analysis finds that managing partnerships uncertainty for sustainable services requires foci that reflect governance structure and relationships climate priorities. These priorities are life-cycle control, resource governance, capability focus and integrative operations with regards to self uncertainty, participative decisions, intervention mechanisms, idea linkage, consumption patterns, communicative structure, clear representations and relationship incentivisation in terms of relationship /behavioural uncertainty, and creativity leveraging, environmental profiling, systemic measuring and process learning as they relate to partner uncertainty. The paper concludes by highlighting research limitations and potential future research directions.
\end{abstract}

Keywords: collaborative networked organisation, sustainability, supply chains, virtual enterprise, product-services systems.

\section{$1 \quad$ Introduction}

Forecasts by organisations such as the United Nations suggest an increasing global population which is estimated to reach 8.9 billion by 2050 [1]. This trend underscores constraints and limitations on the availability of natural resources. The increased level of production and energy consumption due to the rising population also causes concerns due to the earth's inability to accept industrially generated waste. With this in mind, research has intensified into theories and philosophies that concomitantly deliver high quality services, efficiently apply resources, and minimise waste from production and consumption. A sustainable service (e.g. [2] and [3]) is an approach designed to capture this philosophy.

Sustainable services (also known as a 'sustainable product-service systems' [4] or 'eco-efficient product-service systems' [5], [6]), strategise the provision of results or functions and motivates firms to form partnerships and make decisions, under uncertainties, to creatively generate ideas that reduce the environmental impact of companies by factors between 4 and 20 [4]. These partnerships coincide and align with widely acknowledged notions that companies are increasingly competing as part 
of supply chains and partnerships to deliver customer solutions. In spite of this, to date, there has been limited coverage in the literature on the uncertainties that plague partnerships to provide sustainable services. This paper seeks to confront this gap.

The aim of this paper is to propose a conceptual model of partnership uncertainty management for sustainable services. Uncertainty is used in this context, as "the difference in the amount of information that is required to perform a task and the amount of information already possessed by the firm" [7]. Uncertainty is typically associated with production in collaborations such as supply chains [8] and with how sustainability policies are adopted and partners are chosen to deliver sustainable product-service mixes [9]. Consequently, the research is guided by the following research question: What is the nature of uncertainties that characterises industrial collaborations for providing sustainable services?

\section{Background}

In the provision of sustainable services, stakeholder participation is achieved through solution-oriented partnerships (SOPs) i.e. strategic partnerships that share common visions of delivery systems for sustainable services (e.g. [10], [11], [12] and [13]). These partnerships focus on multi-level communications and complex relationships among platform providers, other providers that are needed to complete the system, as well as intermediate- and end-users of the system. Communication and relationships among stakeholders encourages positive attitudes towards selecting products, combining products and services, and formulating regulations that promote lower environmental burden [11], [13]. SOPs - in view of uncertainties of partnerships also fundamentally change producer-consumer relationships towards new notions of sale, ownerships and consumption in which functions are delivered and potentially leads to customer loyalty and innovation that causes behavioural and system-level changes [5], [6].

Uncertainty associated with partnerships is reflected in the variability of governance structure and climate of relationships [12], and researchers have used several terms to characterise this variability, as shown in Fig. 1. For instance, using uncertainty reduction theory, partnership uncertainty has been split into self uncertainty (individual's involvement in relationships), partner uncertainty (variance in partners involvement in a relationship), and relationship uncertainty (variance in the relationship itself) [14]. Relationship uncertainty (also termed behavioural uncertainty) refers to how adaptability partners are to specification changes at short notice and an awareness of partner's resources and goals [15]. Behavioural uncertainty, i.e. the variability of a partner's behaviour or the partner's changes in external environments, is also reflected in performance variations of partners during transactions [12]. While there is a common theme in the literature supporting the need to identify and mitigate uncertainty, these are predominantly studied in relation to manufacturing and product delivery processes [16]. In this article, current research is enhanced through the introduction of a conceptual framework that not only captures the forms of uncertainties that characterise SOPs but also identifies key factors for realising collaborations that provide sustainable services. 


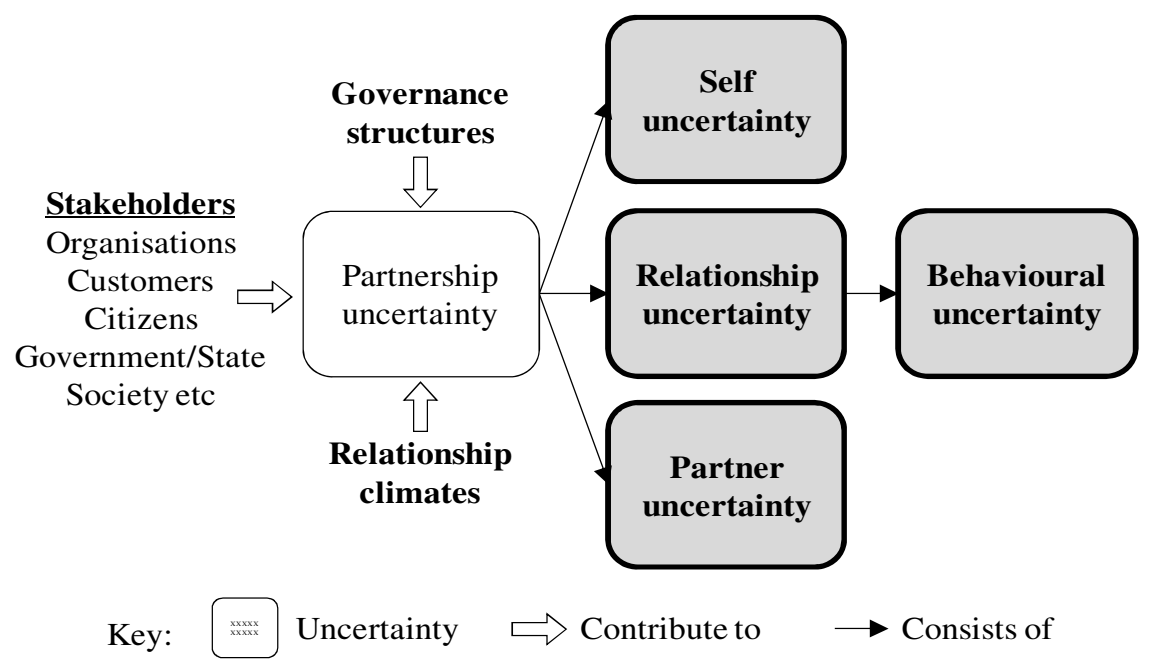

Fig. 1. Research model

\section{$3 \quad$ Method}

In attempt to offer insights into the nature of uncertainties that characterises industrial collaborations for providing sustainable services, this research is driven by the multicase study logic [17] and relies on literature as secondary cases [18]. This logic was chosen because an assessment of the literature suggests limited studies to provide insights into partnership uncertainties for sustainable services. This motivation stirred the research towards case studies in an exploratory approach that captures the 'what's and 'how's of partnership uncertainty for sustainable services. Also, the use of multiple secondary sources was geared towards a holistic view with potentials to unearth uncertainties across discovery, design, development, delivery and disposal phases of service operations. Holistic in used in this context to mean connectedness among characteristics and phenomena, and is required for the integration of sustainable service elements such as goods, equipment, services, information or infrastructure. For this study, 17 research articles were selected based on a search for publications within SCOPUS, ABI/INFORM (ProQuest), Academic Search Premier (EBSCO Host), and ACM Digital Library. Selection involved an initial search and screening process using keywords: "sustainable product-service systems", "ecoefficient product-service systems", and "sustainable service".

Next, using the conceptual framework from Fig. 1, the main findings and discussions of the cases were analysed to shed light on key factors for realising collaborations that provide sustainable services and to refine the research model. This research is therefore positioned within an interpretive epistemology to make sense of partnership uncertainty for sustainable services. By applying the multiple-case logic, a range of management factors was explored and the study generalises at a level of theory as opposed to statistical representativeness or significance. 


\section{$4 \quad$ Findings}

An analysis of the data showed several challenges faced by partnerships for sustainable service provisions, as described in Table 1. These challenges span several individual-, organisational- and institutional-levels of concern and range from humanrelated questions on the consumption patterns of consumers (e.g. [19] and [20]) to innovation-related problems of diffusion and idea generation (e.g. [4], [6] and [21]).

Table 1. Salient partnership uncertainty challenges for providing sustainable services

\begin{tabular}{|c|c|}
\hline Case & Challenges for sustainable service partnerships \\
\hline Halme, Jasch and Scharp [2] & Governance of resources to ease service accessibility \\
\hline Heiskanen and Jalas [3] & $\begin{array}{l}\text { Trajectory of eco-efficient service to establish necessary } \\
\text { intervention mechanisms and to improve design practices }\end{array}$ \\
\hline Roy [4] & Radical process ideas to consolidate waste reduction practices \\
\hline Manzini and Vezzoli [5] & $\begin{array}{l}\text { The development of business ideas that link sustainability to } \\
\text { structural and behavioural changes }\end{array}$ \\
\hline Ceschin [6] & $\begin{array}{l}\text { Socio-technical experiments and societal embedding process } \\
\text { for which actor networks, project visions and learning } \\
\text { processes are critical factors for the diffusion of system } \\
\text { innovation }\end{array}$ \\
\hline Mont [9] & Readiness to adopt and accept sustainable service strategies \\
\hline Krucken and Meroni [10] & Pro-active and participative attitude for customer solutions \\
\hline $\begin{array}{l}\text { Vogtländer, Bijma and Brezet } \\
\text { [11] }\end{array}$ & $\begin{array}{l}\text { Availability and use of information by stakeholders to make } \\
\text { decisions. }\end{array}$ \\
\hline $\begin{array}{l}\text { Evans, Partidário and Lambert } \\
\text { [13] }\end{array}$ & $\begin{array}{l}\text { Realising solutions that incentivise organisations to be } \\
\text { sustainable }\end{array}$ \\
\hline Tukker [19] & Incentives for stakeholders to be sustainable \\
\hline Briceno and Stagl [20] & Alternate consumptions patterns that reflect social strategies \\
\hline Anttonen [21] & $\begin{array}{l}\text { Management to integrate innovation and environmental } \\
\text { policies }\end{array}$ \\
\hline $\begin{array}{l}\text { Maxwell, Sheate and van der } \\
\text { Vorst [22] }\end{array}$ & $\begin{array}{l}\text { Targeting companies for effective management of supply } \\
\text { chains }\end{array}$ \\
\hline Mont [23] & $\begin{array}{l}\text { Consumption behaviour mainly in terms of institutional } \\
\text { factors }\end{array}$ \\
\hline $\begin{array}{l}\mathrm{Hu} \text {, Chen, Hsu, Wang, and Wu } \\
\text { [24] }\end{array}$ & Overcoming barriers to implementing new business models \\
\hline Geum and Park [25] & Clear representations for effective sustainable service design \\
\hline Lee, Geum, Lee and Park [26] & Systematic approach to measuring sustainability \\
\hline
\end{tabular}

Based on the research model in Fig. 1 and findings from the case studies, a conceptual model of partnership uncertainty management was developed, as illustrated in Fig. 2. The figure attempts to map the various management factors (4 for self uncertainty, 7 for relationship /behavioural uncertainty, and 4 for partner 
uncertainty) analysed from the cases according to governance structure and relationships climate management priorities. These next sub-sections present the findings from the analysis under three headings that correspond to the main concepts from the research model in Fig. 1.

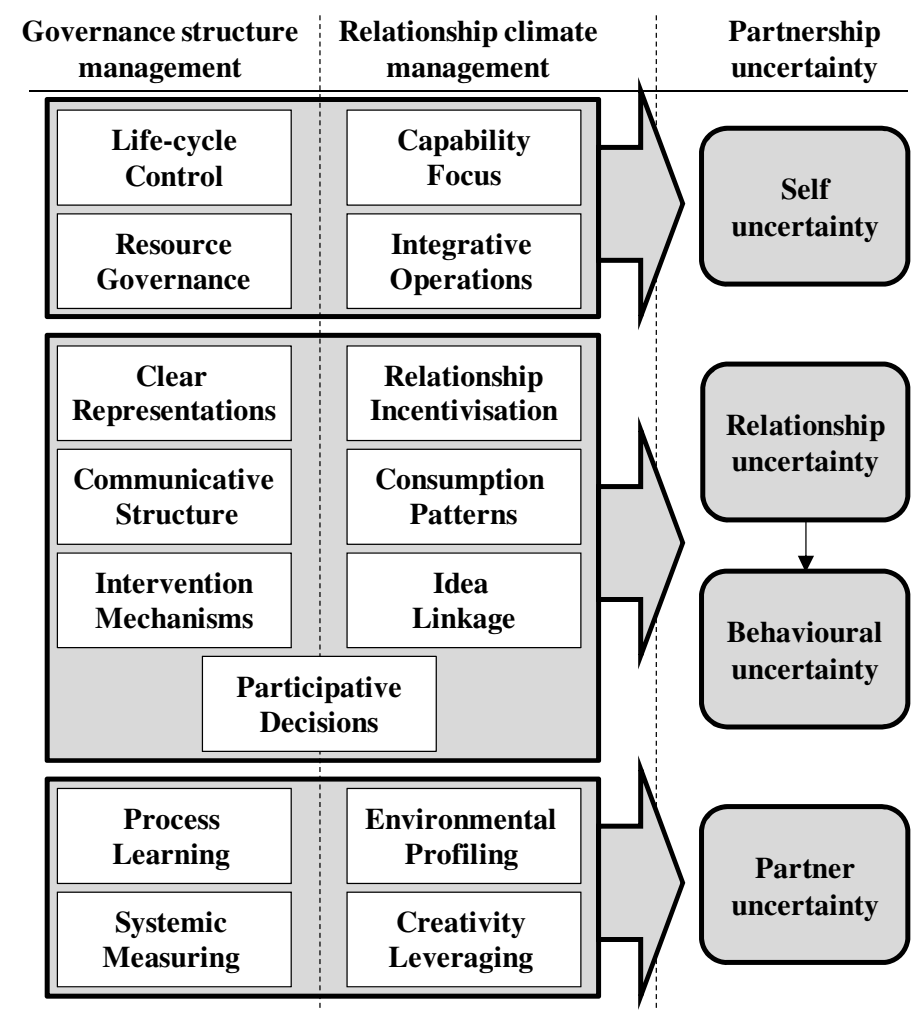

Fig. 2. The management factors model of partnership uncertainty for sustainable services.

\subsection{Self Uncertainty}

Self uncertainty in the cases was reflected in four main management factors: life cycle control, resource governance, capability focus and integrative operations. Life-cycle control is motivated by the need to target companies for the effective management of supply chains for sustainable services. It challenges firms to maintain levels of control (irrespective of size) over key life cycle stages. Resource governance stems from challenges for maintaining effective governance of resources. This factor enables and enhances how stakeholder access services but also heightens the need for institutional arrangements to deliver services directed to households. Capability focus recognises the need to overcome barriers to implementing new business models and stresses the importance of organisational factors relating to management capability and external factors. Integrative operations concentrate on orientations that combine innovation and environmental policies to create service profiles. 


\subsection{Relationship and Behavioural Uncertainty}

Seven main management factors were extracted from the cases relating to relationship and behavioural uncertainty. The first, participative decisions, is concerned with how information is made available and used by stakeholders to make decisions. In this regard, stakeholder (consumers, business managers and governmental representatives) participation to influence eco-efficiency decisions is crucial. The second, intervention mechanisms, is motivated by potential variations in the trajectory of providing ecoefficient service and the influence of company activities on stakeholders. This makes it necessary for interventions, particularly guided by environmental potentials, to be in place to guide and improve service design and delivery practices. The third, idea linkage, prioritises the development of business ideas that link sustainability to structural and behavioural changes and this can be achieved through the involvement of stakeholders along value chains and life cycles. The fourth, consumption patterns, is driven by the need to improve consumption behaviours and emphasises business-toconsumer relationships to deal with unsustainable consumption patterns. Along these lines, alternate consumptions patterns can be formulated with new shared norms, attitudes, and social frameworks that aid in transitions to more sustainable practices. Communicative structure is the fifth factor for operations management and stakeholder empowerment that stresses a combination of pro-active and participative attitudes for effective and efficient delivery of customer solutions. Closely related to communicative structures are clear representations, the sixth factor, that are needed to effectively design sustainable services and to map the behaviour of actors and spatial relationships within delivery networks. The seventh factor, relationship incentivisation, concentrates on fundamentally changing the relationship between stakeholders by offering incentives to be sustainable. Incentives also act as relationship building avenues with clients to enhance customer loyalty.

\subsection{Partner Uncertainty}

With regards to partner uncertainty, four main management factors were captured from the cases: creativity leveraging, environmental profiling, systemic measuring and process learning. Creativity leveraging requires partners to understand and take advantage of creativity within their locus of control for generating radical ideas that promote cleaner processes and consolidate waste reduction practices. Environmental profiling encapsulates how firms are involved and are working closely with different stakeholders to improve product life span and efficiency of resource consumption. This profiling is also important for determining the readiness of a partner to adopt and accept sustainable service strategies. Systemic measuring of sustainability variables is a challenge for firms to develop approaches that measure their sustainability levels and to factor these levels into relationships and communication among stakeholders. Process learning centres on (re)discovering the scientific, social, economic, politic and cultural linkages within the network of actor for delivering sustainable services. It also promotes the use of socio-technical experiments for learning and improving partner's involvement in providing sustainable services. 


\section{Conclusions}

Working at the right time, using the right resources and delivering the right results, is a major challenge for partnerships that requires multiple actors and joint effort. As mentioned earlier, when partnerships are forged for providing sustainable services, these partnerships tend to be plagued by uncertainties that make it difficult to extrapolate from past sustainable service operations - to make forecasts for future sustainable service projects. This is due to differences in variances and variability that create levels of fuzziness for collaboration among partners. Along these lines, this paper has attempted to shed light on "What is the nature of uncertainties that characterises industrial collaborations for providing sustainable services?" Using a research model grounded on literature and findings from secondary case studies, a conceptual model of partnership uncertainty management was developed according to governance structure and relationships climate management priorities.

The paper makes two useful contributions. First, it investigates the nature of partnership uncertainty within operations. Second, the paper analyses orientations for managing partnership uncertainties during the provision of sustainable services. It is however important to stress that practices and policies for uncertainty management should be treated on a case-by-case basis and with respect to leveraging the knowledge of domain experts to better understand uncertainties of transitions to more sustainable and service-oriented operations.

The study is however limited to a qualitative analysis that makes use of 17 secondary case sources and there is a need to widen the scope of the literature investigation. The management model also needs to be applied in real case-studies and quantitative studies to validate the hypothesis. Future cross-sector analyses that investigate trends across industrial sectors are also suggested. While factors of partnership uncertainty management for sustainable services have been highlighted in this study, their significance in short-, medium- and long-structures and behavior has not been ascertained. Future work is therefore needed to study these dynamics and their influences on service encounters, negotiations and innovations. Further research could also use the conceptual model of partnership uncertainty management in studies based on mathematical reasoning, expert systems and decision support systems for generating frameworks, tools and techniques that enhance decisions to join, leave, or remain in solution-oriented partnerships.

\section{References}

1. United Nations, The World at Six Billion (ESA/P/WP.154), Population Division, Department of Economic and Social Affairs, United Nations Secretariat. New York (1999), http://www.un.org/esa/population/publications/sixbillion/ sixbillion.htm

2. Halme, M., Jasch, C., Scharp, M.: Sustainable homeservices? Toward household services that enhance ecological, social and economic sustainability. Ecol. Econ. 51, 125-138 (2004)

3. Heiskanen, E., Jalas, M.: Can services lead to radical eco-efficiency improvements? - A review of the debate and evidence. Corp. Soc. Responsib. Environ. Mgmt. 10, 186-198 (2003) 
4. Roy, R.: Sustainable product-service systems. Futures 32, 289-299 (2000)

5. Manzini, E., Vezzoli, C.: A strategic design approach to develop sustainable product service systems: Examples taken from the 'environmentally friendly innovation' Italian prize. J. Clean Prod. 11, 851-857 (2003)

6. Ceschin, F.: Critical factors for implementing and diffusing sustainable product-Service systems: Insights from innovation studies and companies' experiences. J. Clean Prod. (2013)

7. Galbraith, J.: Designing Complex Organizations. Addison-Wesley, Massachusetts (1973)

8. Davis, T.: Effective supply chain management. Sloan Manage. Rev. 34, 35-46 (1993)

9. Mont, O.K.: Clarifying the concept of product-service system. J. Clean Prod. 10, 237-245 (2002)

10. Krucken, L., Meroni, A.: Building stakeholder networks to develop and deliver productservice-systems: Practical experiences on elaborating pro-active materials for communication. J. Clean Prod. 14, 1502-1508 (2006)

11. Vogtländer, J.G., Bijma, A., Brezet, H.C.: Communicating the eco-efficiency of products and services by means of the eco-costs/value model. J. Clean Prod. 10, 57-67 (2002)

12. Wang, X., Durugbo, C.: Analysing network uncertainty for industrial product-service delivery: A hybrid fuzzy approach. Expert. Syst. Appl. 40, 4621-4636 (2013)

13. Evans, S., Partidário, P.J., Lambert, J.: Industrialization as a key element of sustainable product-service solutions. Int. J. Prod. Res. 45, 4225-4246 (2007)

14. Berger, C.R., Bradac, J.J.: Language and Social Knowledge: Uncertainty in Interpersonal Relationships, London, Arnold (1982)

15. Eriksson, K., Sharma, D.D.: Modeling uncertainty in buyer-seller cooperation. J. Bus. Res. 56, 961-970 (2003)

16. Mason-Jones, R., Towill, D.R.: Shrinking the supply chain uncertainty circle. Control 24, 17-22 (1998)

17. Yin, R.K.: Applications of Case Study Research. Sage, California (1993)

18. Stewart, D.W., Kamins, M.A.: Secondary Research: Information Sources and Methods. Sage, California (1993)

19. Tukker, A.: Eight types of product-service system: Eight ways to sustainability? Experiences from suspronet. Bus. Strat. Environ. 13, 246-260 (2004)

20. Briceno, T., Stagl, S.: The role of social processes for sustainable consumption. J. Clean. Prod. 14, 1541-1551 (2006)

21. Anttonen, M.: Greening from the front to the back door? A typology of chemical and resource management services. Bus. Strat. Environ. 19, 199-215 (2010)

22. Maxwell, D., Sheate, W., van der Vorst, R.: Functional and systems aspects of the sustainable product and service development approach for industry. J. Clean. Prod. 14, 1466-1479 (2006)

23. Mont, O.: Institutionalisation of sustainable consumption patterns based on shared use. Ecol. Econ. 50, 135-153 (2004)

24. Geum, Y., Park, Y.: Designing the sustainable product-service integration: A productservice blueprint approach. J. Clean. Prod. 19, 1601-1614 (2011)

25. Hu, H.A., Chen, S.H., Hsu, C.W., Wang, C., Wu, C.L.: Development of sustainability evaluation model for implementing product service systems. Int. J. Environ. Sci. Te. 9, 343-354 (2012)

26. Lee, S., Geum, Y., Lee, H., Park, Y.: Dynamic and multidimensional measurement of product-service system (PSS) sustainability: A triple bottom line (TBL)-based system dynamics approach. J. Clean. Prod. 32, 173-182 (2012) 